Rio de Janeiro. Ano 16. Volume 23. Número 1. Janeiro a Abril de 2022

Periódico Quadrimestral da Pós-Graduação Stricto Sensu em Direito Processual da UERJ

Patrono: José Carlos Barbosa Moreira (in mem.). ISSN 1982-7636. pp. 695-712

www.redp.uerj.br

\title{
A QUESTÃO DO EFEITO SUSPENSIVO NO RECURSO DE AGRAVO DE INSTRUMENTO EM FACE DA DECISÃO PARCIAL DE MÉRITO1
}

\section{THE QUESTION OF THE SUSPENSIVE EFFECT IN THE APPEAL AGAINST THE PARTIAL EARLY DECISION OF MERIT}

Karen Paiva Hippertt

Pós-graduanda em Direito Constitucional pela Academia Brasileira de Direito Constitucional. Especialista em Processo Civil, Mediação e Arbitragem pela Pontifícia Universidade Católica do Paraná. Graduada em Direito pela Pontifícia Universidade Católica do Paraná - Curitiba. Assessora da Presidência do Tribunal de Justiça do Estado do Paraná - TJPR. Curitiba/PR. E-mail: karen.hippertt@gmail.com.

José Laurindo de Souza Netto Pós-doutor pela Faculdade de Direito da Universidade Degli Studi di Roma La Sapienza. Estágio de Pós-doutorado em Portugal e Espanha. Mestre e Doutor pela Universidade Federal do Paraná - UFPR. Desembargador Presidente do Tribunal de Justiça do Estado do Paraná - TJPR. Curitiba/PR. Email: jln@tjpr.jus.br.

RESUMO: Ao possibilitar o julgamento antecipado parcial do mérito, o Código de Processo Civil cria celeuma no âmbito recursal, por dar tratamento dispare a decisões de idêntico conteúdo, apenas por terem se dado em momentos processuais distintos e em razão de o veículo escolhido pelo legislador para desafiá-las ser diferente. Dentre as diversas problemáticas envolvendo o tema, o trabalho se concentra apenas na questão do efeito suspensivo, tendo por objetivo buscar soluções para a assimetria criada pelo código. Para tanto, utilizou-se o método lógico dedutivo, combinado aos precedentes de pesquisa bibliográfica e documental. Como

\footnotetext{
${ }^{1}$ Artigo recebido em 25/10/2020 e aprovado em 10/06/2021.
} 
principal contribuição do trabalho, tem-se a necessidade de concessão habitual de efeito suspensivo no caso das decisões antecipadas parciais de mérito.

PALAVRAS-CHAVE: Julgamento antecipado parcial de mérito. Recurso cabível. Eficácia da decisão. Efeito suspensivo. Adequação procedimental.

ABSTRACT: By allowing partial early judgment of the merit, the Code of Civil Procedure creates a problem in the appeals field for giving different treatment to two decisions of identical content, only because they occurred in different procedural moments and because the vehicle chosen by the legislator to challenge them are different. Among the various problems involving the issue, the work focuses only on the issue of suspensive effect, aiming to seek solutions to the asymmetry created by the Code. For this, the deductive logical method was used, combined with precedents of bibliographic and documentary research. The main contribution of the work is the need for the usual granting of suspensive effect in the case of partial anticipated decisions of merit.

KEYWORDS: Partial early judgment of merit. Suitable appeal. Effectiveness of the decision. Suspensive effect. Adequacy of the procedure.

SUMÁRIO: 1. Introdução - 2. Julgamento Antecipado Parcial do Mérito e Natureza da Decisão - 3. Recurso Cabível, Efeito Suspensivo e Eficácia Da Decisão - 4. Regime Diferenciado do Recurso de Agravo de Instrumento no tocante ao Efeito Suspensivo - 5. Conclusão - 6. Referências bibliográficas.

\section{INTRODUÇÃO}

A luta do processo contra o tempo não é recente e o tema da cisão do julgamento do mérito adveio justamente da preocupação com a tempestividade da prestação da tutela jurisdicional.

Os dados levantados no relatório "Justiça em Números", elaborado pelo Conselho Nacional de Justiça (CNJ), apontam para um preocupante panorama de crise no Judiciário que 
Revista Eletrônica de Direito Processual - REDP.

Rio de Janeiro. Ano 16. Volume 23. Número 1. Janeiro a Abril de 2022

Periódico Quadrimestral da Pós-Graduação Stricto Sensu em Direito Processual da UERJ

Patrono: José Carlos Barbosa Moreira (in mem.). ISSN 1982-7636. pp. 695-712

www.redp.uerj.br

não consegue entregar a prestação jurisdicional em tempo e condições adequadas.

Na Justiça Estadual, por exemplo, no ano de 2017, um processo em fase de conhecimento demorava cerca de 2 anos e 6 meses até a sentença, e 3 anos e 7 meses para baixa $^{2}$.

O relatório referente ao ano de $2018^{3}$, por seu turno, apontou um tempo médio de tramitação em $2^{\circ}$ grau de 2 anos e 1 mês, e na fase de conhecimento de $1^{\circ}$ grau de 3 anos e 4 meses, o que reflete uma justiça atrasada que distribui mal o ônus do tempo do processo, bem como uma prestação jurisdicional deficitária e injusta que poderá implicar o perecimento de direitos. $^{4}$

Neste contexto, o Código de Processo Civil erigiu como um de seus pilares a busca pela eficiência e razoável duração do processo, materializada por meio da adoção de novos institutos e técnicas. É o caso da solução imediata dos feitos maduros para julgamento, ainda que julgados em mais de um momento ${ }^{5}$, que há muito vinha sendo discutida pela doutrina e jurisprudência, e o código sacramentou de forma expressa nos artigos 354, parágrafo único, e 356.

Na seção que trata sobre o tema, o diploma é claro ao dispor que quando um ou mais pedidos formulados, ou parcela deles, mostrar-se incontroversa, ou estiver em condição de imediato julgamento, sem necessidade de produção de mais provas, o juiz decidirá parcialmente o mérito, garantindo a tutela imediata do direito em consonância com a razoável duração do processo. ${ }^{6}$

Também, não restam dúvidas quanto à natureza desta decisão. Verifica-se que o Código de Processo Civil adotou o critério misto que considera o momento processual em que a decisão é proferida, além de seu conteúdo.

Assim, sentença é todo pronunciamento que põe fim à fase cognitiva do procedimento comum, ou extingue a execução. Já, decisão interlocutória, por consequência, é qualquer

\footnotetext{
${ }^{2}$ Conselho Nacional de Justiça. Justiça em Número 2018: ano-base 2017, Brasília: CNJ, 2018. Disponível em: http://www.cnj.jus.br/files/conteudo/arquivo/2018/08/44b7368ec6f888b383f6c3de40c32167.pdf. Acesso em: 18 ago. 2020.

${ }^{3}$ Conselho Nacional de Justiça. Justiça em Números 2019: ano-base 2018, Brasília: CNJ, 2018. Disponível em: https://www.cnj.jus.br/wp-content/uploads/conteudo/arquivo/2019/08/justica_em_numeros20190919.pdf. Acesso em: 18 ago. 2020.

${ }^{4}$ DIDIER JR, Fredie (Org.). Novo CPC doutrina selecionada: Procedimento comum. v.2. JusPodivm. Salvador, 2016, p. 378.

${ }_{5}^{5}$ DIDIER JR, Fredie (Org.). Novo CPC doutrina selecionada: Procedimento comum. v.2. JusPodivm. Salvador, 2016, p. 369.

${ }^{6}$ MARINONI, Luiz Guilherme. Antecipação da Tutela. 11. ed. São Paulo: Editora Revista dos Tribunais, 2009, p. 283.
} 
Revista Eletrônica de Direito Processual - REDP.

Rio de Janeiro. Ano 16. Volume 23. Número 1. Janeiro a Abril de 2022

Periódico Quadrimestral da Pós-Graduação Stricto Sensu em Direito Processual da UERJ

Patrono: José Carlos Barbosa Moreira (in mem.). ISSN 1982-7636. pp. 695-712

www.redp.uerj.br

decisão que não corresponda a esta descrição (art. 203, §2, $\mathrm{CPC}$ ).

À vista disso, a decisão que julgar o mérito do processo ao final do pleito possuirá natureza de sentença e será atacada por recurso de apelação. Já, a que julgar parcela do mérito em sede antecipada, possuirá natureza interlocutória e será desafiada por recurso de agravo de instrumento. $^{7}$

Ocorre que, apesar da assertividade técnica, o agravo de instrumento não possui diversas das garantias do recurso de apelação, efeito suspensivo ope legis, possibilidade de sustentação oral e tramitação imediata de eventual recurso especial/ extraordinário em caso de apelação, o que, a princípio, evidencia uma disparidade de tratamento infundada adotada pelo código entre a decisão de mérito proferida ao final e àquela dada no meio do processo, apesar de terem o mesmo conteúdo e função.

Dentre as diversas problemáticas envolvendo o tema, o presente estudo irá se debruçar apenas sobre a questão do efeito suspensivo - zona de penumbra na prática forense.

Afinal, no caso das decisões parciais de mérito, deveria se adequar o regime do recurso de agravo de instrumento ao regramento do recurso de apelação, atribuindo-se efeito suspensivo automático, ou de praxe, nestes casos?

Destarte, o trabalho se desenvolverá em três capítulos, para além da conclusão e introdução. O primeiro, compreenderá o instituto do julgamento antecipado parcial de mérito e a natureza da decisão que julga parcela do mérito antecipadamente. $O$ segundo, a recorribilidade, efeito suspensivo e eficácia da decisão recorrida. Por fim, o terceiro, irá investigar o cerne da questão da adoção, ou não, de um regime diferenciado ao recurso de agravo de instrumento no caso das decisões antecipadas parciais de mérito no tocante ao efeito suspensivo.

Para tanto, será feito uso do método lógico dedutivo, combinado aos precedentes de pesquisa bibliográfica e documental.

\section{JULGAMENTO ANTECIPADO PARCIAL DO MÉRITO E NATUREZA DA DECISÃO}

\footnotetext{
${ }^{7}$ NEVES, Daniel Amorim Assumpção. Novo Código de Processo Civil Comentado. 3. ed. atual. Salvador: JusPodivm, 2018, p. 661.
} 
Revista Eletrônica de Direito Processual - REDP.

Rio de Janeiro. Ano 16. Volume 23. Número 1. Janeiro a Abril de 2022

Periódico Quadrimestral da Pós-Graduação Stricto Sensu em Direito Processual da UERJ

Patrono: José Carlos Barbosa Moreira (in mem.). ISSN 1982-7636. pp. 695-712

www.redp.uerj.br

O mister de se obter a prestação de uma tutela jurisdicional célere e efetiva levou o Código de Processo Civil a consagrar de forma expressa a possibilidade da solução fracionada do mérito. ${ }^{8}$

De acordo com o artigo 356 do Código de Processo Civil, o juiz resolverá parcialmente o mérito quando um ou mais pedidos formulados, ou parte deles, for incontroverso (inciso I), ou estiver em condições de resolução imediata (inciso II). ${ }^{9}$

Conforme assevera CÃMARA, "Pode ser que, concluídas as providências preliminares (ou constatado que nenhuma delas era necessária), o juiz se depare com um processo cujo mérito já se encontra em condições de receber imediato julgamento [...]” ${ }^{10}$, neste caso, deverá julgar imediatamente o mérito por meio de decisão antecipada parcial de mérito.

A possibilidade de cisão do mérito trazida pelo Código de Processo Civil veio para sanar disparidade de tratamento entre demandas conexas e acúmulo simples de pedidos, conferindo isonomia e racionalidade. Com a inovação, o demandante que optou por cumular pedido não terá mais de aguardar a produção de todas as provas, mesmo já havendo pedido pronto para julgamento desde o saneamento, para só então, quando todos os pedidos estiverem aptos, obter o bem da vida em sede de sentença final. ${ }^{11}$

Agora, tão logo presentes os requisitos legais para o julgamento antecipado do mérito o juiz estará autorizado a decidir definitiva e antecipadamente o pedido, prosseguindo o feito com relação aos demais que dependam de maior dilação probatória. ${ }^{12}$

Ao consagrar a possibilidade de julgamento imediato do mérito em mais de um momento, o Código de Processo Civil autoriza que o magistrado prolate mais de uma decisão resolvendo o mérito em um mesmo procedimento. Isto é, que fracione a sentença por intermédio de decisão interlocutória de mérito, diante das hipóteses expressamente previstas no artigo 356,

\footnotetext{
${ }^{8}$ CARMONA, Carlos Alberto et al. O Novo Código de Processo Civil: questões controvertidas. [livro eletrônico]. São Paulo: Atlas, 2015.

${ }^{9}$ WAMBIER, Luiz Rodrigues. Curso avançado de processo civil: cognição jurisdicional (processo comum de conhecimento e tutela provisória). vol. 2. 17. ed. São Paulo: Revista dos Tribunais, 2018, p. 206.

${ }^{10}$ CÂMARA, Alexandre Freitas. O Novo Processo Civil Brasileiro. 5. ed. São Paulo: Atlas, 2019. p. 211.

${ }^{11}$ MACHADO, Marcelo Pacheco. Novo CPC: só quero saber de julgamento parcial do mérito. Disponível em: https://www.jota.info/opiniao-e-analise/colunas/novo-cpc/novo-cpc-so-quero-saber-de-julgamento-parcial-d o-merito-26102015. Acesso em: 29 abr. 2020.

12 MACHADO, Marcelo Pacheco. Novo CPC: só quero saber de julgamento parcial do mérito. Disponível em: https://www.jota.info/opiniao-e-analise/colunas/novo-cpc/novo-cpc-so-quero-saber-de-julgamento-parcial-d o-merito-26102015. Acesso em: 29 abr. 2020.
} 
Revista Eletrônica de Direito Processual - REDP.

Rio de Janeiro. Ano 16. Volume 23. Número 1. Janeiro a Abril de 2022

Periódico Quadrimestral da Pós-Graduação Stricto Sensu em Direito Processual da UERJ

Patrono: José Carlos Barbosa Moreira (in mem.). ISSN 1982-7636. pp. 695-712

www.redp.uerj.br

em evidente rompimento com o "mito da unicidade do julgamento da causa" 13 .

Aliás, os comandos do dispositivo legal são, na verdade, mais do que mera autorização. Trata-se de imposição de um dever ao magistrado que deverá julgar antecipadamente o mérito toda vez que diante de uma das circunstâncias do artigo 356, prosseguindo o feito apenas com relação aos perdidos, ou parcela, não apta a julgamento. ${ }^{14}$

Em vista de possibilitar a cisão do mérito, a sistemática do Código de Processo Civil foi alterada inteiramente. Inclusive, modificados os conceitos de sentença e decisão interlocutória, o que ensejou mudanças na sistemática recursal correspondente.

Nos termos do art. $203, \S 1^{\circ}$, do CPC, sentença é o pronunciamento por meio do qual se põe fim à fase cognitiva, ou de execução do processo, e que tem por conteúdo o disposto nos arts. 485, ou 487, do CPC. Já, decisão interlocutória, é todo pronunciamento judicial de natureza decisória que não se enquadre neste conceito ${ }^{15}$. Neste sentido, NERY JUNIOR ${ }^{16}$ :

O pronunciamento do juiz só será sentença se a) contiver uma das matérias previstas no CPC 485 ou $487\left(\mathrm{CPC} 203, \S 1^{\circ}\right)$ e, cumulativamente, b) extinguir a fase cognitiva do processo comum ou a execução (CPC 203, $\S 1^{\circ}$ ), porque se o pronunciamento de natureza decisória for proferido no curso do processo comum ou de execução, isto é, sem que se lhe coloque termo, deverá ser definido como decisão interlocutória [..].

Logo, a decisão que julga parcela do mérito no meio do processo é interlocutória, porquanto a fase cognitiva da parcela do mérito ainda não julgada prosseguirá para a instrução probatória. $^{17}$

Veja-se que, para a classificação dos pronunciamentos judiciais, o Código de Processo Civil adotou o critério misto que considera o momento processual em que a decisão é proferida, além de seu conteúdo ( $\operatorname{art.} 203, \S \S 1^{\circ}$ e $2^{\circ}$ ), razão pela qual não restam dúvidas acerca da natureza interlocutória da decisão que julga imediatamente o mérito no meio do processo, discussão, até mesmo, já superada pela doutrina.

\footnotetext{
${ }^{13}$ MARINONI, Luiz Guilherme et al. Novo Curso de Processo Civil. vol. 2. São Paulo: Revista dos Tribunais, 2016, p. 119.

${ }^{14}$ GONÇALVES, Marcus Vinicius Rios. Direito processual civil esquematizado. 6. ed. São Paulo: Saraiva, 2016, p. 463.

${ }^{15}$ WAMBIER, Luiz Rodrigues. Curso avançado de processo civil: cognição jurisdicional (processo comum de conhecimento e tutela provisória). vol. 2. 17. ed. São Paulo: Revista dos Tribunais, 2018, p. 419.

${ }^{16}$ NERY JUNIOR, Nelson; NERY, Rosa Maria de Andrade. Comentários ao Código de Processo Civil. São Paulo: Editora Revista dos Tribunais, 2015, p.716.

${ }^{17}$ GONÇALVES, Marcus Vinicius Rios. Direito processual civil esquematizado. 6. ed. São Paulo: Saraiva, 2016, p. 547.
} 
Revista Eletrônica de Direito Processual - REDP.

Rio de Janeiro. Ano 16. Volume 23. Número 1. Janeiro a Abril de 2022

Periódico Quadrimestral da Pós-Graduação Stricto Sensu em Direito Processual da UERJ

Patrono: José Carlos Barbosa Moreira (in mem.). ISSN 1982-7636. pp. 695-712

www.redp.uerj.br

Neste sentido, Rodrigo Ramina ${ }^{18}$ :

Considerando que a sentença é o ato que põe fim à fase cognitiva do procedimento comum (art. 203,§ $11^{\circ}$ ), não pode ser sentença $o$ ato que julga $o$ mérito no curso do processo. Não sendo sentença, mas tratando-se de pronunciamento judicial com conteúdo decisório, então o ato é uma decisão interlocutória de mérito (art. 203, § 2. ${ }^{\circ}$ ).

Posto isso, verifica-se que a decisão antecipada parcial de mérito, malgrado resolva o mérito, dispondo das hipóteses dos artigos 485 e 487 do Código de Processo Civil, nos moldes de uma sentença, se fundamente em cognição exauriente, seja proferida após a fase de saneamento, possua natureza definitiva e aptidão para produzir coisa julgada material, não se enquadra no conceito de sentença apenas por razões formais, por não colocar fim por completo ao processo, não porque substancialmente, sob o prisma do seu conteúdo, não equivalha a uma sentença, inclusive, pondo fim à parcela do mérito sobre a qual decide. ${ }^{19}$

Assim, a verdade é que se trata de decisão híbrida, formalmente de caráter interlocutório, mas com conteúdo essencial de sentença. ${ }^{20}$

\section{RECURSO CABÍVEL, EFEITO SUSPENSIVO E EFICÁCIA DA DECISÃO}

Igualmente, não há dúvidas acerca do recurso cabível. Tratando-se de decisão interlocutória, nos termos do $\S 5^{\circ}$ do art.356 do CPC, a decisão que julgar parcela do mérito antecipadamente será impugnada por recurso de agravo de instrumento. Neste aspecto, algumas ponderações devem ser feitas.

O efeito suspensivo atribuído aos recursos impede que a decisão produza de imediato seus efeitos. No entanto, a regra geral adotada pelo código é a de que os recursos não impedem a eficácia da decisão, isto é, não possuem efeito suspensivo ope legis, ou melhor, por força de lei (art. 995, CPC). ${ }^{21}$

\footnotetext{
${ }^{18}$ DE LUCCA, Rodrigo Ramina. Julgamentos antecipados parciais de mérito. Revista de Processo. v. 257 , n. 2016, p. 125-150, 2016.

${ }^{19}$ LEMOS, Vinicius Silva. O agravo de instrumento contra decisão parcial de mérito. In: Revista de Processo. 2016. Disponível em: http://www.mpsp.mp.br/portal/page/portal/documentacao_e_divulgacao/doc_bi blioteca/bibli_servicos_produtos/bibli_boletim/bibli_bol_2006/RPro_n.259.12.PDF. Acesso em: 18 ago. 2020.

${ }^{20}$ LEMOS, Vinicius Silva. O agravo de instrumento contra decisão parcial de mérito. In: Revista de Processo. 2016. Disponível em: http://www.mpsp.mp.br/portal/page/portal/documentacao_e_divulgacao/doc_bi blioteca/bibli_servicos_produtos/bibli_boletim/bibli_bol_2006/RPro_n.259.12.PDF. Acesso em: 18 ago. 2020. ${ }^{21}$ WAMBIER, Luiz Rodrigues; TALAMINI, Eduardo. Curso avançado de processo civil: cognição jurisdicional (processo de conhecimento e tutela provisória). v. 2. 16. ed. reformada e ampliada de acordo com o novo CPCSão Paulo: Editora Revista dos Tribunais, 2016, p. 494.
} 
Revista Eletrônica de Direito Processual - REDP.

Rio de Janeiro. Ano 16. Volume 23. Número 1. Janeiro a Abril de 2022

Periódico Quadrimestral da Pós-Graduação Stricto Sensu em Direito Processual da UERJ

Patrono: José Carlos Barbosa Moreira (in mem.). ISSN 1982-7636. pp. 695-712

www.redp.uerj.br

Não obstante, o referido efeito pode decorrer da lei (ope legis), a exemplo do recurso de apelação, ao qual a lei atribuiu efeito suspensivo automático no art. 1.012, ou de decisão judicial que o conceda (ope judicis), como no caso do agravo de instrumento (art. 1. 019, I, CPC).

No tocante ao efeito suspensivo ope legis, seu fundamento reside na incerteza acerca da assertividade da decisão de primeiro grau. Busca-se uma menor chance de erros para garantir maior segurança jurídica. ${ }^{22}$

Fredie Didier ${ }^{23}$ destaca que, neste caso, o efeito suspensivo, seria espécie de medida cautelar para fins de evitar o considerável risco de dano ${ }^{24}$ caso a decisão de mérito proferida ao final do processo produzisse seus efeitos de imediato e viesse futuramente a ser modificada em sede recursal.

Em contrapartida, observa-se que, no caso do recurso de agravo de instrumento, a lei não atribuiu efeito automático, razão pela qual a decisão por ele impugnada surte efeitos tão logo publicada, ainda que pendente recurso (art. 995, caput, CPC). ${ }^{25}$

Destarte, a decisão que julga parcela do mérito antecipadamente, embora possua conteúdo decisório tal qual o de uma sentença, desde logo, irá produzir seus efeitos, ficando a mercê da concessão do efeito suspensivo pelo relator, ante o requerimento da parte e desde que preenchidos cumulativamente os requisitos da probabilidade do direito e perigo de dano (art. $995, \mathrm{CPC})^{26}$, em um latente regime de eficácia privilegiado em se comparado ao da sentença. 27

Por seu turno, a decisão que julga o mérito ao final do processo segue lógica completamente inversa, ante a mera recorribilidade ${ }^{28}$. Já nasce ineficaz e apenas produzirá seus efeitos após não interposto o correspondente recurso, ou ante sua rejeição, única e

\footnotetext{
${ }^{22}$ BERMUDES, Sérgio. Considerações sobre o efeito suspensivo dos recursos cíveis. Revista da EMERJ, v.3, n.11, 2000, p. 67-68. Disponível em: http://www.emerj.tjrj.jus.br/revistaemerj_online/edicoes/revista11/revista1 1.pdf. Acesso em: 18 ago. 2020.

${ }^{23}$ MOREIRA, José Carlos Barbosa. Comentários ao Código de Processo Civil. 17. ed. Rio de Janeiro: Forense, 2013. vol. 5. p. 469-472.

${ }^{24}$ DIDIER JUNIOR, Fredie. Curso de Direito Processual Civil. 9. ed. v. 2. Salvador: Juspodivm, 2014. p. 137.

${ }^{25}$ BUENO, Cassio Scarpinella. Manual de direito processual civil: volume único. 4. ed. São Paulo: Saraiva Educação, 2018.

${ }^{26}$ WAMBIER, Luiz Rodrigues; TALAMINI, Eduardo. Curso avançado de processo civil: teoria geral do processo. 16. ed. São Paulo: Revista dos Tribunais, 2016. vol. 1. p 547.

${ }^{27}$ LUCON, Paulo Henrique dos Santos; OLIVEIRA, Pedro Miranda de. Panorama atual do novo CPC. Florianópolis: Empório do Direito, 2017, p. 502.

${ }^{28}$ MOREIRA, José Carlos Barbosa. Comentários ao Código de Processo Civil. 17. ed. Rio de Janeiro: Forense, 2013. vol. 5. p. 469-472.
} 
Revista Eletrônica de Direito Processual - REDP.

Rio de Janeiro. Ano 16. Volume 23. Número 1. Janeiro a Abril de 2022

Periódico Quadrimestral da Pós-Graduação Stricto Sensu em Direito Processual da UERJ

Patrono: José Carlos Barbosa Moreira (in mem.). ISSN 1982-7636. pp. 695-712

www.redp.uerj.br

exclusivamente pelo fato de ser desafiada por recurso de apelação ao qual o código concedeu efeito suspensivo ope legis, é a regra disposta no caput do artigo 1.012, excetuados os casos expressos em lei $\left(\S 1^{\circ}\right)$.

À vista disso, observa-se que o Código de Processo Civil conferiu especial atenção à materialização dos princípios da efetividade, celeridade e eficiência, contudo deixou de lado a segurança jurídica, o devido processo legal e proporcionalidade, dando tratamento dispare injustificadamente a duas decisões com o mesmo conteúdo, apenas por terem sido proferidas em momentos processuais distintos.

Por isso, Marcelo Pacheco Machado ${ }^{29}$ destaca que o Código de Processo Civil corrige disparidade do Código de 1973, ao possibilitar a cisão do mérito, mas acaba criando nova discrepância e, agora, no âmbito recursal. Dispondo, na sequência, só querer saber de julgamento parcial de mérito que, neste contexto, se apresenta como um prêmio, já que os atos decisórios atacados por meio de agravo produzem imediatamente seus efeitos, diferentemente, do "grande castigo" de se receber uma sentença favorável que, em regra, possui eficácia suspensa, apenas em razão de ser atacada por apelação.

\section{REGIME DIFERENCIADO DO RECURSO DE AGRAVO DE INSTRUMENTO NO TOCANTE AO EFEITO SUSPENSIVO}

Como dito, a decisão que julga parcela do mérito antecipadamente possui conteúdo idêntico ao da decisão dada ao final do processo, uma vez que proferida com base em cognição exauriente e possuir aptidão para produzir coisa julgada material. ${ }^{30}$

Nesta seara, injustificada a diferença de tratamento adotada pelo Código de Processo Civil ao conceder regime de eficácia privilegiado ${ }^{31}$ à decisão que possui o mesmo conteúdo decisório daquela dada ao final do processo, apenas por ter sido proferida em momento processual distinto e em razão de o veículo escolhido pelo legislador ser outro. Uma completa

\footnotetext{
${ }^{29}$ MACHADO, Marcelo Pacheco. Novo CPC: só quero saber de julgamento parcial do mérito. Disponível em: https://www.jota.info/opiniao-e-analise/colunas/novo-cpc/novo-cpc-so-quero-saber-de-julgamento-parcial-do-m erito-26102015. Acesso em: 18 ago. 2020.

${ }^{30}$ LUCON, Paulo Henrique dos Santos; OLIVEIRA, Pedro Miranda de. Panorama atual do novo CPC. Florianópolis: Empório do Direito, 2017, p. 502.

31 LUCON, Paulo Henrique dos Santos; OLIVEIRA, Pedro Miranda de. Panorama atual do novo CPC. Florianópolis: Empório do Direito, 2017, p. 502.
} 
Revista Eletrônica de Direito Processual - REDP.

Rio de Janeiro. Ano 16. Volume 23. Número 1. Janeiro a Abril de 2022

Periódico Quadrimestral da Pós-Graduação Stricto Sensu em Direito Processual da UERJ

Patrono: José Carlos Barbosa Moreira (in mem.). ISSN 1982-7636. pp. 695-712

www.redp.uerj.br

violação aos princípios da isonomia processual e segurança jurídica ${ }^{32}$. Neste sentido, Pedro Miranda de Oliveira ${ }^{33}$ :

[...] na interpretação dos dispositivos de um Código, é sempre imprescindível procurar coerência, a fim de que dele emane um sistema. Seria absolutamente assistemático e incoerente supor que a decisão parcial de mérito, apenas porque foi proferida por meio de um julgamento antecipado (interlocutória de mérito) tenha eficácia imediata, enquanto uma sentença (concedida ao final) não tem esse atributo.

Para mais, se o fundamento para a concessão de efeito suspensivo ope legis no caso do recurso de apelação é a ideia de cautela visando evitar o considerável risco de dano caso a decisão de mérito produza seus efeitos de imediato e venha futuramente a ser modificada em sede recursal ${ }^{34}$, e há identidade de conteúdo entre as referidas decisões, não subsistem razões para se deixar de atribuir, senão automaticamente, de praxe, o efeito suspensivo.

Seria ilógico pressupor, para fins de justificar o tratamento diferenciado adotado pelo diploma legal, que o mencionado fundamento esteja presente em uma situação e não em outra, considerando serem estas idênticas.

Igualmente, desproporcional a submissão de decisão com conteúdo idêntico ao de uma sentença a regime equivalente ao do recurso de agravo de instrumento, previsto para atacar decisão interlocutória que não possui esse conteúdo especial, sem nenhum ajuste ou adequação.

Inclusive, essa é a premissa por de trás da paridade de tratamento, “[...] assegurada às partes em relação ao exercício de direitos e faculdades processuais, aos meios de defesa, aos ônus, aos deveres e à aplicação de sanções processuais [...]" ${ }^{35}$, norma fundamental no Código de Processo Civil e cláusula constitucional na forma do caput do artigo $5^{\circ}$ da Constituição Federal.

Também, aí reside um dos fundamentos para que o juiz, requerido pela parte, nos moldes do regramento previsto em lei para o recurso de agravo, conceda de modo habitual o efeito suspensivo, uma vez que o próprio Código de Processo Civil a ele confia a tarefa fundamental de assegurar que às partes verdadeiramente disponham dos instrumentos processuais. Isto é,

\footnotetext{
${ }^{32}$ WAMBIER, Luiz Rodrigues; TALAMINI, Eduardo. Curso Avançado de Processo Civil. v. 2 [livro eletrônico] . 5. ed. São Paulo: Editora Revista dos Tribunais, 2016.

${ }^{33}$ LUCON, Paulo Henrique dos Santos; OLIVEIRA, Pedro Miranda de. Panorama atual do novo CPC. Florianópolis: Empório do Direito, 2017, p. 433.

${ }^{34}$ MOREIRA, José Carlos Barbosa. Comentários ao código de processo civil, lei $n^{\circ} 5.869$, de 11 de janeiro de 1973, vol. V: arts. 476 a 565. Rio de Janeiro: Forense, 2008. p. 469-472.

${ }^{35}$ BRASIL. Lei no 13.105 , de 16 de março de 2015. Instituiu o Código de Processo Civil. Diário Oficial da União, Brasília, 17 de março de 2015. Disponível em: http://www.planalto.gov.br/ccivil_03/_ato20152018/2015/lei/113105.htm. Acesso em: 18 ago. 2020.
} 
Revista Eletrônica de Direito Processual - REDP.

Rio de Janeiro. Ano 16. Volume 23. Número 1. Janeiro a Abril de 2022

Periódico Quadrimestral da Pós-Graduação Stricto Sensu em Direito Processual da UERJ

Patrono: José Carlos Barbosa Moreira (in mem.). ISSN 1982-7636. pp. 695-712

www.redp.uerj.br

atribuí ao magistrado a incumbência de materializar a simetria processual, diante das problemáticas oriundas da aplicação da norma. ${ }^{36}$

Destarte, esse é o entendimento compartilhado por grande parcela da doutrina que defende à adoção de um regime diferenciado ao recurso de agravo de instrumento interposto em face de decisão com especial conteúdo, para fins de manter a coerência e simetria do sistema.

Neste ínterim, Pedro Miranda de Oliveira entende que, nestes casos, o efeito suspensivo é automático, igual ao da apelação, decorrente naturalmente do art. 1.012 do CPC, já que em se tratando de decisões idênticas deve ser conferida a mesma chance de rediscussão da matéria sem a produção dos efeitos da decisão atacada. ${ }^{37}$

Igualmente, Rogério Molica e Elias Marques de Medeiros Neto entendem que o recurso de agravo deveria ser recebido com duplo efeito, admitindo-se o efeito suspensivo automático. 38

O Ceapro também compartilha deste entendimento, conforme o Enunciado $13^{39}$ : "O efeito suspensivo automático do recurso de apelação, aplica-se ao agravo de instrumento interposto contra a decisão parcial do mérito prevista no art. 356 (artigo 1.015)”.

Em sentido contrário, Vinicius da Silva Lemos sustenta que, ante a ausência de previsão legal, impossível a concessão automática do efeito suspensivo, razão pela qual este deve ser concedido habitualmente na forma procedimental do agravo, "com viés de interpretação pela necessidade - e não possibilidade - do relator conceder para igualar as situações recursais [...]" ${ }^{40}$, entendimento adotado no presente trabalho.

Por brevidade, sob o fundamento da ausência de previsão legal, nos moldes do sustentado por Vinicius da Silva Lemos, o Tribunal de Justiça de Minas Gerais, em recentíssima decisão, deixou de acolher a tese do efeito suspensivo ex lege:

\footnotetext{
${ }^{36}$ CARMONA, Carlos Alberto et al. O Novo Código de Processo Civil: questões controvertidas. [livro eletrônico]. São Paulo: Atlas, 2015.

37 LUCON, Paulo Henrique dos Santos; OLIVEIRA, Pedro Miranda de. Panorama atual do novo CPC. Florianópolis: Empório do Direito, p. 433, 2017.

${ }^{38}$ MOLICA, Rogerio. NETO, Elias Marques de Medeiros. Afinal: o agravo de instrumento interposto contra a decisão parcial de mérito do art. 356 do novo CPC deve ser admitido com efeito suspensivo automático do artigo 1.012 do novo CPC?. Disponível em: https://www.migalhas.com.br/CPCnaPratica/116,MI264632,71043Afinal+o+agravo+de+instrumento+interposto+contra+a+decisao+parcial+de. Acesso em: 29. Abr. 2019.

${ }^{39}$ Disponível em: http://www.ceapro.org.br/enunciados.html. Acesso em: 18 ago. 2020.

${ }^{40}$ LEMOS, Vinicius Silva. O agravo de instrumento contra decisão parcial de mérito. In: Revista de Processo. 2016. Disponível em: http://www.mpsp.mp.br/portal/page/portal/documentacao_e_divulgacao/doc_biblioteca/bi bli_servicos_produtos/bibli_boletim/bibli_bol_2006/RPro_n.259.12.PDF. Acesso em: 18 ago. 2020.
} 
Revista Eletrônica de Direito Processual - REDP.

Rio de Janeiro. Ano 16. Volume 23. Número 1. Janeiro a Abril de 2022

Periódico Quadrimestral da Pós-Graduação Stricto Sensu em Direito Processual da UERJ

Patrono: José Carlos Barbosa Moreira (in mem.). ISSN 1982-7636. pp. 695-712

www.redp.uerj.br

AGRAVO INTERNO EM AGRAVO DE INSTRUMENTO. DECISÃO PARCIAL DE MÉRITO. AGRAVO DE INSTRUMENTO. EFEITO SUSPENSIVO EX LEGE. INEXISTÊNCIA. ANALOGIA COM APELAÇÃO. IMPOSSIBILIDADE. AGRAVO IMPROVIDO. DECISÃO MANTIDA. Em vista de previsão legislativa específica para a concessão de efeito suspensivo para Agravo de Instrumento, é indevida integração legal por meio de analogia para aplicar, para o recurso mencionado, a norma que rege a apelação"- (TJMG- AGT: 10000181199316002, Relator: José Marcos Vieira, Data de Julgamento: 28/03/2019, Dje: 29/03/2019).

Assim, constata-se que o Juízo ad quem optou por aplicar o regramento próprio do recurso de agravo de instrumento por considerar indevida a integração legal por meio de analogia.

Neste sentido, cabe enfatizar o entendimento adotado. Se não concedido automaticamente o efeito suspensivo por ausência de previsão legal, que o seja de praxe, na forma prevista no código para o recurso de agravo, não "só com o viés de interpretação pela necessidade - e não possibilidade - do relator conceder para igualar as situações recursais [...]" ${ }^{41}$, mas também porque se o fundamento para a concessão do efeito suspensivo automático na sentença é o risco de dano ${ }^{42}$ e, portanto, a necessidade de cautela por si só já é tida como suficiente para a concessão automática do efeito suspensivo no caso do recurso de apelação, tratando-se de decisões idênticas, o fundamento também se faz presente a sustentar a concessão habitual, no caso do agravo de instrumento em face da decisão antecipada parcial de mérito. Afora isso, considerando o próprio dever que tem o magistrado de materializar a simetria processual e assegurar os demais princípios, para além da pura e simples celeridade processual.

Ainda, equivocada a afirmação, calcada em viés mais positivista, de que o sistema jurídico pode tratar situações idênticas de modo diferente, optando por tornar mais importante a decisão antecipada parcial de mérito do que a sentença, sem violação à isonomia, e que se assim o fez não cabe ao aplicador fazê-lo. ${ }^{43}$

Com a constitucionalização do Direito Processual Civil o processo não pode mais ser visto como estanque, o intérprete deve sempre fazer uma leitura orientada pela Constituição Federal. Aliás, é o que dispõe expressamente o artigo $1^{\circ}$ do Código de Processo Civil.

\footnotetext{
${ }^{41}$ LEMOS, Vinicius Silva. O agravo de instrumento contra decisão parcial de mérito. In: Revista de Processo. 2016. Disponível em: http://www.mpsp.mp.br/portal/page/portal/documentacao_e_divulgacao/doc_biblioteca/bi bli_servicos_produtos/bibli_boletim/bibli_bol_2006/RPro_n.259.12.PDF. Acesso em: 18 ago. 2020.

${ }^{42}$ DIDIER JUNIOR, Fredie. Curso de Direito Processual Civil. 9. ed. v. 2. Salvador: Juspodivm, 2014. p. 137.

${ }^{43}$ Cf. SILVA, Beclaute Oliveira; DA SILVA, Ivan Luiz; ARAÚJO, José Henrique Mouta. Eficácia do agravo de instrumento na decisão antecipada parcial de mérito. Revista Eletrônica de Direito Processual, v. 17, n. 2, 2016.
} 
Revista Eletrônica de Direito Processual - REDP.

Rio de Janeiro. Ano 16. Volume 23. Número 1. Janeiro a Abril de 2022

Periódico Quadrimestral da Pós-Graduação Stricto Sensu em Direito Processual da UERJ

Patrono: José Carlos Barbosa Moreira (in mem.). ISSN 1982-7636. pp. 695-712

www.redp.uerj.br

Destarte, partindo-se de uma análise constitucionalizada do processo, não se pode deixar de lado os princípios da isonomia processual e segurança jurídica, apenas se pautando em uma legalidade e celeridade vazias. Conforme bem destaca Teresa Arruda Alvim “[...] pode ser absolutamente desastrosa a insistência em manter o raciocínio orientado exclusivamente pelo método clássico de pensar" ${ }^{44}$.

Nota-se, ainda, que de nada basta à busca por uma celeridade a qualquer custo, porquanto inócua. Inclusive, esta lógica vai de encontro à própria exposição de motivos do código a qual dispõe que "a celeridade não é um valor que deva ser perseguido a qualquer custo" 45 .

Por arremate, em se tratando o Código de Processo Civil de um sistema, necessariamente, a investigação da problemática deve se dar à luz da análise do todo, tornando inevitável a correção da ausência de sistematicidade e coerência do código por meio da concessão habitual do efeito suspensivo automático, no caso das decisões antecipadas parciais de mérito.

\section{CONCLUSÃO}

O Código de Processo Civil erigiu como um de seus pilares a busca pela eficiência e razoável duração do processo, adotando novos institutos e técnicas, como é o caso do julgamento antecipado do mérito, disposto no artigo 356.

Neste ínterim, o diploma legal sacramentou de forma expressa a possibilidade do julgamento antecipado do mérito no artigo 356, prosseguindo o feito apenas com relação aos perdidos, ou parcela, não apta a julgamento. ${ }^{46}$

Ato contínuo, para possibilitar a cisão do mérito, a sistemática do código foi inteiramente alterada, com modificação dos conceitos de decisão interlocutória e sentença, o que interferiu no âmbito da sistemática recursal.

Destarte, sentença é todo pronunciamento que põe fim à fase cognitiva do procedimento

\footnotetext{
${ }^{44}$ WAMBIER, Teresa Arruda Alvim. Nulidades do Processo e da Sentença. 6. ed. São Paulo: RT, 2007. p. 493.

${ }^{45}$ BRASIL. Lei no 13.105 , de 16 de março de 2015. Instituiu o Código de Processo Civil. Diário Oficial da União, Brasília, 17 de março de 2015. Disponível em: https://www2.senado.leg.br/bdsf/bitstream/handle/i d/512422/001041135.pdf. Acesso em: 18 ago. 2020.

${ }^{46}$ GONÇALVES, Marcus Vinicius Rios. Direito processual civil esquematizado. 6. ed. São Paulo: Saraiva, 2016. p. 463.
} 
Revista Eletrônica de Direito Processual - REDP.

Rio de Janeiro. Ano 16. Volume 23. Número 1. Janeiro a Abril de 2022

Periódico Quadrimestral da Pós-Graduação Stricto Sensu em Direito Processual da UERJ

Patrono: José Carlos Barbosa Moreira (in mem.). ISSN 1982-7636. pp. 695-712

www.redp.uerj.br

comum, ou extingue a execução. Decisão interlocutória é, então, por exclusão, qualquer decisão que não corresponda a esta descrição (art. 203, §2º CPC).

Assim, com adoção do critério misto, que considera o momento processual em que a

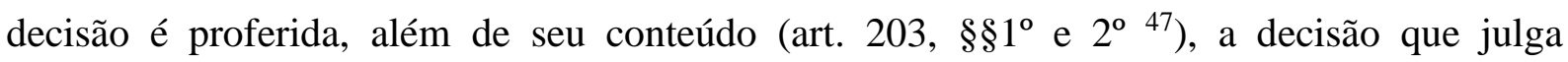
imediatamente o mérito no meio do processo é classificada como decisão interlocutória, apesar do especial conteúdo de sentença e, portanto, é desafiada por recurso de agravo de instrumento com "regime de eficácia privilegiado" ${ }^{48}$, em razão de o recurso de agravo não possuir efeito suspensivo automático.

Por seu turno, a decisão de mérito localizada ao final do processo segue lógica completamente inversa. Por ser atacada por recurso de apelação, dotado de efeito suspensivo ope legis, já nasce ineficaz, nos moldes do caput do artigo 1.012 do Código de Processo Civil, excetuadas as hipóteses legais $\left(\$ 1^{\circ}\right)$.

Assim, verifica-se que o código acabou por buscar uma celeridade a qualquer custo, dando tratamento dispare injustificadamente a decisões de mesmo conteúdo decisório, apenas por terem sido proferidas em momentos processuais distintos.

Desta forma, a partir da leitura de doutrinas, artigos e códigos comentados, o presente trabalho buscou solucionar a zona de penumbra criada no dia a dia forense, respondendo ao questionamento acerca de qual tratamento deveria ser adotado no tocante ao efeito suspensivo, nestes casos.

Concluiu-se que, uma vez que a decisão que julga parcela do mérito antecipadamente apresenta o mesmo conteúdo da decisão dada ao final do processo, ao passo que proferida com base em cognição exauriente e possua aptidão para produzir coisa julgada material ${ }^{49}$, seria ilógico e assistemático conferir-lhe tratamento dispare apenas por ter se dado em momento processual distinto e em razão de o veículo escolhido pelo legislador ser outro, o que viola, até mesmo, os princípios da isonomia processual e segurança jurídica. ${ }^{50}$

\footnotetext{
${ }^{47}$ BRASIL. Lei no 13.105 , de 16 de março de 2015. Instituiu o Código de Processo Civil. Diário Oficial da União, Brasília, 17 de março de 2015. Disponível em: http://www.planalto.gov.br/ccivil_03/_ato20152018/2015/lei/113105.htm. Acesso em: 18 ago. 2020.

${ }^{48}$ LUCON, Paulo Henrique dos Santos; OLIVEIRA, Pedro Miranda de. Panorama atual do novo CPC. Florianópolis: Empório do Direito, 2017. p. 502.

${ }^{49}$ LUCON, Paulo Henrique dos Santos; OLIVEIRA, Pedro Miranda de. Panorama atual do novo CPC. Florianópolis: Empório do Direito, 2017. p. 502.

50 WAMBIER, Luiz Rodrigues; TALAMINI, Eduardo. Curso Avançado de Processo Civil, vol. 2 [livro eletrônico]. 5. ed. São Paulo: Editora Revista dos Tribunais, 2016.
} 
Revista Eletrônica de Direito Processual - REDP.

Rio de Janeiro. Ano 16. Volume 23. Número 1. Janeiro a Abril de 2022

Periódico Quadrimestral da Pós-Graduação Stricto Sensu em Direito Processual da UERJ

Patrono: José Carlos Barbosa Moreira (in mem.). ISSN 1982-7636. pp. 695-712

www.redp.uerj.br

Contudo, não há como sustentar por equiparação que o efeito suspensivo decorreria do próprio artigo 1.012 do Código de Processo Civil, que trata do recurso de apelação, ante a ausência de previsão legal e considerando que na práxis forense essa tese seria facilmente afastada. Inclusive, foi o que fez o Tribunal de Justiça de Minas Gerais ao julgar o agravo interno em agravo de instrumento de $\mathrm{n}^{\mathrm{o}} 10000181199316002^{51}$.

Deste modo, a melhor alternativa para combater à assistematicidade, sem fugir do regramento próprio previsto em lei para o recurso de agravo de instrumento, seria a concessão habitual de efeito suspensivo ao agravo de instrumento que ataca decisão antecipada parcial de mérito, quando requerido pela parte, “com viés de interpretação pela necessidade - e não possibilidade - do relator conceder para igualar as situações recursais" ${ }^{52}$, com os seguintes fundamentos: (1) tratando- se de decisões de idêntico conteúdo, deve ser garantido tratamento isonômico, respeitados os princípios da isonomia processual, previsto como norma fundamental no Código de Processo Civil e como cláusula constitucional na forma do caput do artigo $5^{\circ}$ da Constituição Federal, e segurança jurídica; (2) se o fundamento para a atribuição de efeito suspensivo automático na sentença é o risco de dano ${ }^{53} \mathrm{e}$, portanto, a necessidade de cautela por si só já é tida como suficiente para a concessão automática do efeito suspensivo no caso do recurso de apelação, tratando-se de decisões idênticas, o fundamento também se faria presente a sustentar a concessão de praxe no caso do recurso de agravo de instrumento em face da decisão antecipada parcial de mérito; (3) o próprio Código de Processo Civil confia ao magistrado a tarefa fundamental de assegurar que às partes disponham verdadeiramente dos instrumentos processuais, ou seja, lhe incumbe de materializar a simetria processual diante das problemáticas oriundas da aplicação da norma ${ }^{54}$; (4) com a constitucionalização do Direito Processual Civil o processo não pode mais ser visto como estanque, o intérprete deve sempre fazer uma leitura orientada pela Constituição Federal, até mesmo por força do artigo $1^{\circ}$ do Código de Processo Civil; (5) a problemática deve ser analisada a partir do Código de Processo Civil como um sistema; (6) a própria disposição de motivos do Código de Processo dispõe que "a celeridade

\footnotetext{
${ }^{51}$ TJMG. Agravo de Instrumento: AGT 10000181199316002. Relator: José Marcos Vieira. Dj: 28/03/2019. Dje: 29/ 03/2019.

${ }^{52}$ LEMOS, Vinicius Silva. O agravo de instrumento contra decisão parcial de mérito. In: Revista de Processo. 2016. Disponível em: http://www.mpsp.mp.br/portal/page/portal/documentacao_e_divulgacao/doc_biblioteca/bi bli_servicos_produtos/bibli_boletim/bibli_bol_2006/RPro_n.259.12.PDF. Acesso em: 18 ago. 2020.

${ }^{53}$ DIDIER JUNIOR, Fredie. Curso de Direito Processual Civil. 9. ed. v. 2. Salvador: Juspodivm, 2014. p. 137.

${ }^{54}$ CARMONA, Carlos Alberto et al. O Novo Código de Processo Civil: questões controvertidas. [livro eletrônico]. São Paulo: Atlas, 2015.
} 
Revista Eletrônica de Direito Processual - REDP.

Rio de Janeiro. Ano 16. Volume 23. Número 1. Janeiro a Abril de 2022

Periódico Quadrimestral da Pós-Graduação Stricto Sensu em Direito Processual da UERJ

Patrono: José Carlos Barbosa Moreira (in mem.). ISSN 1982-7636. pp. 695-712

www.redp.uerj.br

não é um valor que deva ser perseguido a qualquer custo". 55

\section{REFERENCIAS:}

BERMUDES, Sérgio. Considerações sobre o efeito suspensivo dos recursos cíveis. Revista da EMERJ, v.3, n.11, 2000, p. 67-68. Disponível em: http://www.emerj.tjrj.jus.br /revistaemerj_online/edicoes/revista11/revista11.pdf. Acesso em: 18 ago. 2020.

BUENO, Cassio Acarpinella. Manual de direito processual civil: volume único. 4.ed., São Paulo: Saraiva Educação, 2018.

CÂMARA, Alexandre Freitas. O Novo Processo Civil Brasileiro. 5. ed. São Paulo: Atlas, 2019. p. 211.CARMONA, Carlos Alberto et al. O Novo Código de Processo Civil: questões controvertidas. [livro eletrônico]. São Paulo: Atlas, 2015.

CONSELHO NACIONAL DE JUSTIÇA. Justiça em Número 2018: ano-base 2017. Brasília:

CNJ, 2018. Disponível em: http://www.cnj.jus.br/files/conteudo/arquivo/201 8/08/44b7368ec6f888b383f6c3de40c32167.pdf. Acesso em: 18 ago. 2020.

CONSELHO NACIONAL DE JUSTIÇA. Justiça em Números 2019: ano-base 2018. Brasília:

CNJ, 2018. Disponível em: https://www.cnj.jus.br/wpcontent/uploads/conteudo/arqui vo/2019/08/justica_em_numeros20190919.pdf. Acesso em: 18 ago. 2020.

DE LUCCA, Rodrigo Ramina. Julgamentos antecipados parciais de mérito. Revista de Processo, v. 257, n. 2016. Disponível em: http://www.mpsp.mp.br/portal/page/ portal/documentacao_e_divulgacao/doc_biblioteca/bibli_servicos_produtos/bibli_bole tim/bibli_bol_2006/RPro_n.257.10.PDF. Acesso em: 18 ago. 2020.

DIDIER JR, Fredie (Org.). Novo CPC doutrina selecionada: procedimento comum. v. 2. JusPodivm. Salvador, 2016.

DIDIER JR, Fredie; BRAGA, Paula Sarno; DE OLIVEIRA, Rafael Alexandria. Curso de Direito Processual Civil. 9. ed. v. 2. Salvador: Juspodivm, 2014.

DIDIER JR, Fredie; BRAGA, Paula Sarno; DE OLIVEIRA, Rafael Alexandria. Curso de direito processual civil: teoria da prova, direito probatório, decisão, precedente, coisa julgada e tutela provisória. 13. ed., Salvador: Ed. Jus Podivim, 2018. v.2.

\footnotetext{
55 BRASIL. Lei no 13.105, de 16 de março de 2015. Instituiu o Código de Processo Civil. Diário Oficial da União, Brasília, 17 de março de 2015. Disponível em: https://www2.senado.leg.br/bdsf/bitstream/handle/id 1512422/001041135.pdf. Acesso em: 18 ago. 2020.
} 
GONÇALVES, Marcus Vinicius Rios. Direito processual civil esquematizado. 6. ed. São Paulo: Saraiva, 2016. p. 463.

JÚNIOR, Humberto Theodoro. Curso de Direito Processual Civil. 59. ed. Rio de Janeiro: Forense, 2018.

LEMOS, Vinicius Silva. O agravo de instrumento contra decisão parcial de mérito. In: Revista de Processo. 2016. Disponível em: http://www.mpsp.mp.br/portal/page/portal /documentacao_e_divulgacao/doc_biblioteca/bibli_servicos_produtos/bibli_boletim/bi bli_bol_2006/RPro_n.259.12.PDF. Acesso em: 18 ago. 2020.

LUCON, Paulo Henrique dos Santos; OLIVEIRA, Pedro Miranda de. Panorama atual do novo CPC. Florianópolis: Empório do Direito, 2017.

MACHADO, Marcelo Pacheco. Novo CPC: só quero saber de julgamento parcial do mérito. Disponível em: https://www.jota.info/opiniao-e-analise/colunas/novo-cpc/novo-cpcso-quero-saber-de-julgamento-parcial-do-merito-26102015. Acesso em: 18 ago. 2020.

MARINONI, Luiz Guilherme. Antecipação da Tutela. 11 ed. São Paulo: Editora Revista dos Tribunais, 2009.

MARINONI, Luiz Guilherme; ARENHART, Sérgio Cruz; MITIDIERO, Daniel. Novo Curso de Processo Civil. v. 2. São Paulo: Revista dos Tribunais, 2016.

MOLICA, Rogerio. NETO, Elias Marques de Medeiros. Afinal: o agravo de instrumento interposto contra a decisão parcial de mérito do art. 356 do novo CPC deve ser admitido com efeito suspensivo automático do artigo 1.012 do novo CPC?. Disponível em: https://www.migalhas.com.br/CPCnaPratica/116,MI264632,71043Afinal+o+agra vo+de+instrumento+interposto+contra+a+decisao+parcial+de. Acesso em: 18 ago. 2020.

MOREIRA, José Carlos Barbosa. Comentários ao Código de Processo Civil. 17. ed. Rio de Janeiro: Forense, 2013. vol. 05.

NERY JUNIOR, Nelson; NERY, Rosa Maria de Andrade. Comentários ao Código de Processo Civil. São Paulo: Editora Revista dos Tribunais, 2015.

NEVES, Daniel Amorim Assumpção. Novo Código de Processo Civil Comentado. 3.ed. ver. atual. Salvador: Ed. JusPodivm, 2018.

SILVA, Beclaute Oliveira; DA SILVA, Ivan Luiz; ARAÚJO, José Henrique Mouta. Eficácia do agravo de instrumento na decisão antecipada parcial de mérito. 
Revista Eletrônica de Direito Processual - REDP.

Rio de Janeiro. Ano 16. Volume 23. Número 1. Janeiro a Abril de 2022

Periódico Quadrimestral da Pós-Graduação Stricto Sensu em Direito Processual da UERJ

Patrono: José Carlos Barbosa Moreira (in mem.). ISSN 1982-7636. pp. 695-712

www.redp.uerj.br

Revista Eletrônica de Direito Processual, v. 17, n. 2, 2016. Disponível em: https://www.e-publicacoes.uerj.br/index.php/redp/article/view/25679. Acesso em: 18 ago. 2020.

WAMBIER, Luiz Rodrigues. Curso avançado de processo civil: cognição jurisdicional (processo comum de conhecimento e tutela provisória), v. 2. 17. ed. São Paulo: RT.

WAMBIER, Luiz Rodrigues; TALAMINE, Eduardo. Curso avançado de processo civil: teoria geral do processo. 16. ed. São Paulo: Revista dos Tribunais, 2016. vol. 1.

WAMBIER, Luiz Rodrigues; TALAMINE, Eduardo. Curso Avançado de Processo Civil, vol. 2 [livro eletrônico]. 5. ed. São Paulo: Editora Revista dos Tribunais, 2016.

WAMBIER, Teresa Arruda Alvim. Nulidades do Processo e da Sentença. 6. ed. São Paulo: RT, 2007. 